\title{
Multivariate analyses of factors associated with unemployment in people with multiple sclerosis
}

\author{
Marit Grønning, Einar Hannisdal, Svein Ivar Mellgren
}

\begin{abstract}
Variables at onset of multiple sclerosis (MS) as prédictors of time to unemployment have been studied using multivariate survival (time-to-response) analyses. The study consisted of 79 patients with MS diagnosed in the two most northern counties of Norway between 1974-82. Diagnostic category, age at onset, sex, county, symptom groups, course of disease and occupation groups were identified as possible prognostic variables. Forty one patients $(51 \%)$ were unemployed at last follow up. None of the 15 patients with probable or possible MS were unemployed due to MS. The multivariate analyses selected the nonremittent course or heavy physical work and age over 30 at onset as high risk factors associated with early unemployment.
\end{abstract}

Multiple sclerosis is the most frequent disabling neurological disease in young people. MS runs a protracted course and has many sociomedical implications. Mitchell ${ }^{1}$ found that $40 \%$ of MS patients among Post Office employees had retired on medical grounds and unemployment severe enough to cause retirement had developed more rapidly when the disease had been diagnosed late in life. La Rocca et $a l^{2}$ found that older and more educated males were most likely to maintain employment. In an interview study of 949 patients where $46 \%$ had an observation time of more than 10 years from diagnosis, mobility dysfunction was significantly correlated to employment status. ${ }^{3}$ In 1978 , 1565 patients in Norway received a disability pension because of MS. $^{4}$ The life table method $^{5}$ and Cox regression model $^{6}$ are univariate and multivariate time-to-response analyses mainly used in survival studies of cancer patients. We have used these analyses to examine the following question: can patient characteristics at the onset of MS indicate high risk patients for subsequent unemployment?

\section{Material and methods}

This study of MS patients, living in the two northern-most counties of Norway, Troms and Finnmark, was carried out in 1983. It is based on patient files recorded during 1974 82 at the University Hospital of Tromsø. In 1983 the population of the area was 225073 .
Further characteristics of the area have been described in a previous paper on MS epidemiology. ${ }^{7}$

The whole area is served by one department of neurology, opened in 1967. The neurological services in the area expanded during the 1970s with the establishment of a university neurological department and an extensive, decentralised outpatient service. ${ }^{8}$ There are no neurologists in private practice. Because of the decentralised outpatient service, the patients had easy access to neurological services and most of them are seen regularly, at one to two year intervals.

Eighty patients were diagnosed in the region. In one patient occupational data were missing and this patient was excluded from further analyses. The diagnosis was based on criteria as published by Rose et $a l^{9}$ and classified as clinically definite MS, probable MS and possible MS (64, seven and eight patients, respectively). The patients were also grouped according to the clinical course of the disease ${ }^{7}$ as remittent, remittent-progressive and progressive MS (49, 12 and 18 respectively) (table 1). All 15 patients with probable or possible MS were in the remittent group.

The study population consisted of 44 females and 35 males with an age at onset ranging from 13 to 55 with a mean age of 30 years. The patients were divided into three main occupation groups, housewives (16), light work (34) and heavy work (29). Secretaries, nurses, teachers, engineers and drivers were included in the light work category. Two students were included in this group. Sailors, industrial workers, fishermen and craftsmen were classified as heavy workers. Three patients who had changed work after the onset of MS were classified according to their occupation at the time of the onset of MS. Patients with heavy physical work were more frequently found in the non-remittent group (17 of 29 patients).

Table 1 Some variables at diagnosis and unemployment in multiple sclerosis

\begin{tabular}{llcr}
\hline & & \multicolumn{2}{c}{$\begin{array}{l}\text { Unemployed at last } \\
\text { follow up }\end{array}$} \\
\cline { 3 - 4 } $\begin{array}{l}\text { Variables at } \\
\text { diagnosis }\end{array}$ & $n$ & $n$ & $\%$ \\
\hline Probable-possible MS & 15 & 0 & 0 \\
Definite MS & 64 & 46 & 72 \\
Remittent form & 49 & 18 & 37 \\
Non-remittent & 30 & 28 & 93 \\
Heavy work & 29 & 25 & 86 \\
Light work & 50 & 21 & 42 \\
Age $\leqslant 30$ & 50 & 26 & 52 \\
Age $>30$ & 29 & 20 & 69 \\
\hline
\end{tabular}


The year of onset of the disease is defined as the year of the first symptom(s); this ranged from 1947 to 1982. Employment status is defined as whether or not an individual receives disability pension. Observation time from the onset to the last follow up varied from one to 33 years with a mean of 10 years. Six patients had died and three had moved from the area. Two patients with $50 \%$ disability pension and five under rehabilitation at the last follow up were regarded as unemployed. Possible prognostic variables for predicting unemployment were assessed at the time of the onset of the disease.

Differences between employment curves were tested with the logrank test. ${ }^{10}$ The Cox proportional hazards model allows the simultaneous analysis of the importance of several prognostic factors. ${ }^{6}$ The Cox model has one main assumption: proportional hazards. ${ }^{11}$ The mathematical background with examples of proportional hazards is described in greater detail elsewhere. ${ }^{112}$ Proportionality was checked graphically. ${ }^{13}$ The only continuous variable tested was age. A threshold of 30 years-two age groups-gave the best fit of the proportional plots. The plots of three groups for the variables clinical course and occupation groups did not satisfy the proportional assumption in contrast to the grouping presented in table 2 . The eight variables included in the multivariate analysis are shown in table 2 . A probability value of $<0.05$ was considered statistically significant. All analyses were performed with the BMDPC87 computer programme. ${ }^{13}$

\section{Results}

All patients were employed or performing their work at the onset of MS. Forty one of $79(51 \%)$ of patients were unemployed at the last follow up (table 1). Five and ten years after the onset of MS $65 \%$ and $54 \%$, respectively, were still employed (fig 1). In univariate analysis of time to unemployment definite MS ( $p<0.001$ ), the non-remittent group $(p<0.01)$, heavy physical work $(\mathrm{p}<0.01)$, male sex $(\mathrm{p}<0.05)$ and age over 30 at onset $(p<0.01)$ were associated with shorter employment time (table 2 ). None of the 15 patients with probable or possible MS had retired, and thus a variable with definite MS versus probable or possible MS was not feasible in the multivariate

Table 2 Uni-and multivariate analyses of factors associated with time to unemployment in multiple sclerosis

\begin{tabular}{|c|c|c|c|}
\hline \multirow[b]{2}{*}{ Possible prognostic factors } & \multirow{2}{*}{$\frac{\text { Univariate }}{\text { Analyses }}$} & \multicolumn{2}{|c|}{ Multivariate } \\
\hline & & Analyse 1 & Analyse 2 \\
\hline $\begin{array}{l}\text { Diagnosis category } \\
\text { Definite } v \text { probable-possible } \\
\text { Clinical course }\end{array}$ & $\mathrm{p}<0.001$ & Not tested & \\
\hline $\begin{array}{l}\text { Remittent } v \text { non-remittent } \\
\text { Occupation groups } \quad \text { Housewives }\end{array}$ & $\mathrm{p}<0.01$ & $p<0.01$ & Not tested \\
\hline $\begin{array}{ll}\text { and light work } v \text { heavy } & \text { work } \\
\text { Age } & \leqslant 30 v>30 \\
\text { Sex } & \text { Females } v \text { males } \\
\text { Counties } & \text { Troms } v \text { Finnmark } \\
\text { Brain stem symptom(s) } & \text { No } v \text { yes } \\
\text { Paresis(es) } & \text { No } v \text { yes } \\
\text { Sensory disturbance(s) } & \text { No } v \text { yes }\end{array}$ & $\begin{array}{l}p=0.01 \\
p=0.05 \\
p<0.05 \\
\text { NS } \\
\text { NS } \\
\text { NS } \\
\text { NS }\end{array}$ & $\begin{array}{l}\text { NS } \\
\text { NS } \\
\text { NS } \\
\text { NS } \\
\text { NS } \\
\text { NS } \\
\text { NS }\end{array}$ & $\begin{array}{l}p<0.01 \\
\text { p }<0.05 \\
\text { NS } \\
\text { NS } \\
\text { NS } \\
\text { NS } \\
\text { NS }\end{array}$ \\
\hline
\end{tabular}

The group defined first had better prognosis, that is, remittent better than non-remittent. NS: Not significant.

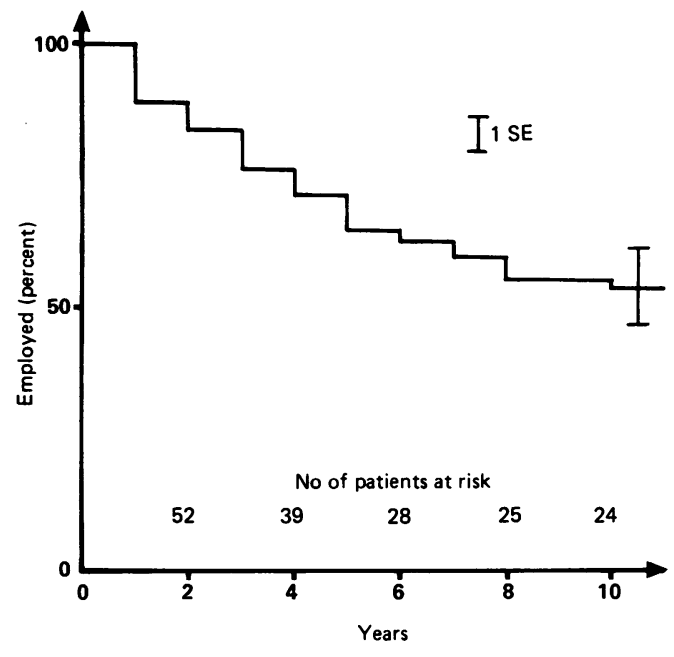

Figure Years from the onset of multiple sclerosis to unemployment in the two most northern counties of Norway (Life table curve, $n=79$ ).

analyses programme. The multivariate analyses were run with and without the variable "clinical course" as this variable in some cases was not obvious at diagnosis. When included, the clinical course was the only significant prognostic factor selected. Multivariate analysis without clinical course selected occupation group and age as the only prognostic factors (table 2).

\section{Discussion}

Diagnostic category, clinical course, occupation group and age were the strongest predictors of time to unemployment. For some patients information about the clinical course was available only after diagnosis. It may be questionable to let the clinical course compete in multivariate analyses together with other variables recorded only at the time of diagnosis. On the other hand, the clinical course is a commonly used characteristic of MS patients. This conflict was met by doing two multivariate analyses; with and without the clinical course.

The factors associated with early unemployment were partly correlated to each other. All the 15 patients with non-definite MS were in the remittent group. Heavy work was more frequently found in the non-remittent group and explains the selection of either clinical course or occupation group as prognostic factors in the multivariate analyses. The finding of the clinical course as a prognostic factor agrees with other studies which have shown that a progressive course increases the risk of early disablement. ${ }^{1415}$

High age ( $>30$ years) at onset of MS was a significant predictor of early unemployment. This has also been demonstrated by others. ${ }^{134-16}$ Older patients may have a biologically more malignant type of MS. Furthermore, it is well known that rehabilitation tends to be less successful for older patients. Heavy physical work also indicated shorter employment time; housewives, however, maintained their employment status longest. This is probably due to more flexibility 
in their work, an assumption also made by Norwegian law which demands a higher degree of disability in this group for them to be eligible for disability pension.

In this study $51 \%$ of the MS patients were unemployed due to their condition before compulsory retirement at the age of 67 years. In the studies of Mitchell, ${ }^{1} \mathrm{La} \mathrm{Rocca}^{2}$ and Kornblith ${ }^{3}$ $40 \%, 77 \%$ and $80 \%$ respectively, were unemployed. The differences in employment rates probably reflect various patient selections and perhaps more important: differing observation times from the onset of the disease. The life table (survival) analyses which we have used, are designed to solve the latter problem; the analyses take account of the decreasing number of patients at risk (for unemployment) as observation times increase. One of the studies deals with MS in Post Office employees. ${ }^{1}$ Our study has the advantage of including the total population of MS patients in a geographically defined area.

In the multivariate analyses, gender and the initial symptoms were not significant prognostic factors, as found by Confavreux..$^{14} \mathrm{Sex}$ as a variable produced conflicting results. ${ }^{216}$ Our study showed the best prognosis was for housewives and patients with light physical work. Females constituted the majority in both these groups, and in the univariate analysis females had a significantly longer employment time.

This report concludes that patients with a non-remittent clinical course, aged 30 years and over, and heavy physical work should be considered as high risk patients for early unemployment due to MS.

1 Mitchell JN. Multiple sclerosis and the prospects for employment. J Sos Occup Med 1981;31:134-8.

2 La Rocca N, Kalb R, Scheinberg L, Kendall P. Factors associated with unemployment of patients with multiple sclerosis. J Chron Dis 1985;38:203-10.

3 Kornblith AB, La Rocca NG, Baum HM. Employment in individuals with multiple sclerosis. Int $J$ Rehab Research 1986;9:155-65.

4 Westlund K. Recent statistical data on multiple sclerosis and some other diseases in Norway. Nordic Council Arct Med Res Rep 1982;32:19-29.

5 Cuthler S, Ederer F. Maximum utilization of the life table method in analyzing survival. J Chron Dis 1958;8: 699-712.

6 Cox DR. Regression models and life-tables. $J R$ Stat Soc 1972;34:187-220.

7 Gronning M, Mellgren SI. Multiple sclerosis in the two northernmost counties of Norway. Acta Neurol Scand 1985;72:321-7.

8 Haldorsen T, Mellgren SI, Rolstad $\emptyset$. Decentralised outpatient neurology service in the county of Finnmark; an analysis of costs compared with a centralized service. Acta Neurol Scand 1984;69:61-2.

9 Rose AS, Ellison GW, Myers LW, Tourtellotte WW. Criteria for the clinical diagnosis of multiple sclerosis. Neurology 1976;26:20-2.

10 Peto R, Pike C, Armitage P, et al. Design and analysis of clinical trials requiring prolonged observation of each patient. Br J Cancer 1977;35:1-39.

11 Elashoff JD. Surviving proportional hazards. Hepatology 1983;3:1031-5.

12 Schlicting P, Christensen E, Andersen PK, et al. Prognostic factors in cirrhosis identified by Cox's regression model. Hepatology 1983;3:889-95.

13 Dixon WJ. BMDP statistical software. Berkeley: University of California Press, 1985.

14 Confavreux C, Aimard G, Devic M. Course and prognosis of multiple sclerosis assessed by the computerized data processing of 349 patients. Brain 1980;103:281-300.

15 Leibowitz V, Alter M. Clinical factors associated with increased disability in multiple sclerosis. Acta Neurol Scand 1970;46:53-70.

16 Detels R, Clark VA, Valdiviezo NL, Visscher BR, Malmgren RM, Dudley JP. Factors associated with rapid course of multiple sclerosis. Arch Neurol 1982; 39:337-41. 